\title{
FERNANDO HENRIQUE CARDOSO: TEORIA DA DEPENDÊNCIA E TRANSIÇÃO DEMOCRÁTICA
}

\author{
FERNANDO LIMONGI
}

Estamos reunidos hoje para celebrar a obra de Fernando Henrique Cardoso. Viemos prestar uma homenagem, manifestar publicamente o reconhecimento dos membros do Cebrap à contribuição feita por Fernando Henrique Cardoso às ciências sociais. Se integrássemos o comitê do Prêmio Kluge teríamos feito a mesma escolha.

Pediram-me para fazer uma breve apresentação da obra do nosso homenageado. Aênfase foi no breve. Prometo: serei breve. Mas o breve justifica as escolhas arbitrárias que fiz na reconstituição da trajetória intelectual de Fernando Henrique Cardoso. Se omito esta ou aquela obra, se passo ao largo deste ou daquele momento de sua carreira, é simplesmente porque estou sendo obediente. Trata-se de uma breve reconstituição. Necessariamente idiossincrática.

Ainda que estejamos celebrando a obra acadêmica de Fernando Henrique Cardoso, impossível esquecer do político, do político que ocupou a presidência da República. Não há como deixar de refletir sobre as duas carreiras trilhadas e, mais do que isso, sobre o notável sucesso alcançado em ambas. Há de se convir que não é pouca coisa. Poucos receberam o Prêmio Kluge e poucos ocuparam a presidência da República.

Recuperando o clima intelectual em que Fernando Henrique Cardoso se formou, a referência aos conhecidos e justamente famosos ensaios de Max Weber sobre a política e a ciência como vocações é inescapável. Para todos aqueles que se formaram no interior da tradição das ciências sociais da USP, tradição esta que Fernando Henrique Cardoso tanto ajudou a criar, esses ensaios são, por assim dizer, leitura básica e obrigatória. Todos os lemos. Fernando Henrique, com certeza, os usou como bibliografia em seus cursos. Fernando Henrique assina a revisão técnica de uma das traduções desses trabalhos publicada no Brasil.

São dois ensaios. Para Weber, e não apenas para Weber, seriam duas carreiras distintas, sem comunicação imediata. O cientista e o político teriam ethos próprios, teriam que atender a reclamos de ordem diversa. Seus comprometimentos envolveriam lógicas distintas. 
Não é minha intenção ir adiante nessa remissão. Para além de ser breve, não pretendo chateá-los. Essas referências vagas são suficientes para o que pretendo estabelecer como ponto de partida: Fernando Henrique Cardoso refuta a tese. Trilhou ambas as carreiras e o fez com distinção. Mais do que isso, como procurarei mostrar, Fernando Henrique pautou sua atuação nesses dois campos por uma única convicção. A ética de que se valeu, contudo, não foi aprendida com o sociólogo alemão ou em qualquer outro livro.

O certo é que não faltam cientistas, sobretudo cientistas sociais, que se lançaram na carreira política. Tampouco há escassez de políticos mal sucedidos, em fim de carreira, que após serem derrotados pelas urnas buscam refúgio na academia. Há muitos dublês de políticos e acadêmicos. A questão está em obter sucesso em ambas as carreiras. Albert O. Hirschman, com toda a sua erudição, em visita ao Cebrap logo após a eleição de 1994, não foi capaz de citar muitos cientistas convertidos a políticos de sucesso. Não passou de um par de casos, contando-os nos dedos da mão.

Pois bem, como essas duas vocações puderam ser aliadas? Como foi possível chegar ao ponto mais alto em ambas?

O fato é que no início de sua carreira como cientista, seria muito difícil vislumbrar a mais remota possibilidade de que o jovem professor viria a se candidatar ao Senado e, posteriormente, chegar à presidência. Como todos sabem, o uso do avental era mandatório na Faculdade de Filosofia, Ciências e Letras. A ciência estava no centro. Fazer ciência era o objetivo maior.

Que era este o objetivo, que o compromisso era com a ciência,é algo que é afirmado e reafirmado por todos os membros daquela ilustre geração. Não há entrevista ou memória do período, das reconstituições mais leves às mais elaboradas, em que se deixe de notar que na Maria Antônia se buscava fazer ciência, ciência com maiúsculas e em negrito. Aqueles que vieram a ser identificados como os representantes da Escola Paulista de Sociologia, os sociólogos reunidos em torno de Florestan Fernandes, buscavam manter uma distância, digamos, profilática da política.

Pode ser um exagero, mas, desses depoimentos, a ideia que se faz do grupo é a de que seguiam à risca os ensinamentos de Weber e tantos outros: a atividade científica pede isolamento da política militante. A ciência só floresce quando protegida por uma série de casamatas penosamente construídas e defendidas. De outra forma, estariam negadas as condições para a atividade científica, para a definição de uma agenda de pesquisas ditada por sua própria lógica. Só assim o rigor da atividade científica suplanta o ensaísmo. Por essas razões, como todos sabemos, a Escola Paulista de Sociologia e o Iseb seriam antípodas, opostos pelo vértice. 
Não que a ciência que praticavam não fosse engajada ou não estivesse atenta à realidade social e política brasileira. Antes o contrário. Tratava-se de fazer uma ciência comprometida com entender as transformações sociais em curso; a formação da sociedade de classes no Brasil. No máximo, no ethos desses cientistas, em uma leitura mannheimiana das relações entre ciência e política, caberia influenciar e dirigir esse processo.

Ainda que assim fosse, ainda que buscasse influenciar a mudança, a ciência social almejada era uma que se resguardasse das relações diretas com o mundo político. Cátedra e palanque não se misturavam. Não deveriam se misturar. A cátedra pedia o avental branco.

Se assim foi no princípio, se essa era a ambição original do cientista social, como entender a entrada na política? Na realidade, há uma questão prévia, anterior, que pede resposta. Por que um grupo de cientistas sociais tão confessadamente apolítico acaba sendo afastado da universidade? Por que afinal foram cassados?

Quando das comemorações de quarenta anos de fundação do Cebrap, em meio aos inúmeros depoimentos que colhemos naquela oportunidade, eu coloquei essa questão ao Giannotti. Por que vocês foram cassados se não estavam metidos na política? A resposta, e talvez não tenha sido bem isto que o Giannotti me disse, mas foi assim que eu entendi, foi que a cassação teria se dado em função da atuação no Conselho Universitário da USP. A política universitária, e não a partidária, teria sido a causa do afastamento da universidade e da punição política. Mas o que realmente me chamou a atenção foi o complemento à resposta, um comentário sem maiores pretensões, jogado ao ar: "Na verdade, quem de fato fazia política era o Fernando. Eleera o único a conversar com a direita, entender o que eles queriam. A gente não conseguia entender as razões por trás das posições da direita. $\mathrm{O}$ Fernando Henrique conversava com todo mundo, negociava. Por isso, estava fazendo um baita estrago".

Já faz algum tempo que tivemos essa conversa. Não sei se a reprodução é fiel. Não importa. Mas para quem leu O presidente segundo o sociólogo não há como não se lembrar da passagem em que o então presidente relembra os ensinamentos de seu pai: "O meu pai dizia era que nunca se devia deixar de falar com o carcereiro. Nas diversas vezes em que ele foi preso nunca deixou. [...] Mesmo preso, você tem que falar, não deixar o adversário longe. Tem que falar o tempo todo. E com

[1] Cardoso, Fernando Henrique. O presidente segundo o sociólogo. São Paulo: Companhia das Letras, 1998 , p.342. o guarda, não com o capitão" ${ }^{\text {. }}$.

Essas reflexões, que bem poderiam ter sido feitas por Riobaldo, ou outro personagem qualquer de Guimarães Rosa, para fazer referência a um autor que Fernando Henrique Cardoso reverencia, são cruciais para entender as duas carreiras, a ponte que liga uma a outra. Deve-se conversar com todo mundo, sobretudo com o carcereiro. Ele, o guarda, 
é central para trazer as notícias do mundo. Eé isto que distingue os grandes intelectuais e os grandes políticos: a capacidade de receber e processar as notícias do mundo.

Ouvir e compreender as diferentes opiniões - argumentos e razões -, incluindo a dos adversários, é algo sempre saudado entre os políticos. É uma característica citada com frequência para explicar carreiras políticas bem-sucedidas. Um bom político precisa ser capaz de ouvir. Digamos, esse ponto é consensual e podemos dá-lo como estabelecido. Que essas sejam qualidades necessárias para um bom intelectual, contudo, creio eu, nem sempreé notado. Por vezes, parece-me, aponta-se na direção contrária, criando-se um ideal de intelectual que se aferra a suas ideias de forma intransigente, como se o intelectual precisasse acreditar em suas ideias com o fervor de um sacerdote.

A abertura para receber notícias do mundo écrucial para o cientista social, equivale à recusa de se acomodar, a se contentar com as explicações dogmáticas, prontas e acabadas. Para tanto, é preciso que ouça e entenda os argumentos, independentemente de quem os enuncia.

Pois muito bem, tendo feito esta longa introdução, tendo estabelecido este ponto de partida, posso passar à breve apresentação da obra que me foi solicitada. Contando com esse pano de fundo, é possível identificar o fio condutor das diversas contribuições de Fernando Henrique às ciências sociais. A sua característica maior é o questionamento constante, a recusa à resposta fácil, negar a explicação convencional, negar o dogmatismo.

Serei específico. Vou citar exemplos. Escolhi duas contribuições para ilustrar a caracterização que acabei de fazer. Nessas duas oportunidades, nessas duas contribuições, Fernando Henrique Cardoso chacoalhou paradigmas estabelecidos, desafiou a explicação convencional, dispôs-se a pensar livremente, escapando do conforto que a reprodução do já conhecido oferece. E, como mostrarei, no segundo caso, voltou-se contra as suas próprias ideias. Isto é, Fernando Henrique Cardoso contribuiu para revisar as contribuições que fizera no passado e que, perigosamente, começaram a ser tratadas como dogmas. Difícil, ao meu ver, encontrar exemplo maior de grandeza intelectual.

Aos exemplos. O primeiro, como não poderia deixar de ser, é a teoria da dependência. Sem dúvida alguma, se há um trabalho ou obra que se associa imediatamente a Fernando Henrique, esta obra é Dependência e desenvolvimento na América Latina, escrita em 1966, no exílio, no Chile, em coautoria com Enzo Faletto.

Para as gerações atuais, e mesmo para a minha, é difícil explicar a ruptura contida nessa obra. Difícil porque todos somos, por assim dizer, aspas, "dependentistas". Nós pensamos dentro desse modelo. Queiramos ou não. Fomos educados — para os mais velhos, reeducados - dentro desse paradigma. Respiramos teoria da dependên- 
[2] Cardoso, Fernando Henrique, Faletto, Enzo. Dependência e desenvolvimento na América Latina. Rio de Janeiro: Zahar, 1970, p. 34. cia. Seu sucesso foi tamanho que as teses que a obra rejeitou foram relegadas ao completo esquecimento. As que não foram inteiramente esquecidas são lidas de outra forma, são, hoje, compatibilizadas com a teoria da dependência. $O$ contraste e a ruptura foram esmaecidos, e tudo se passa como se uma leitura marxista da história da América Latina fosse automaticamente cunhada nos termos postos pela teoria da dependência.

Para mostrar o que há de novo em Dependência e desenvolvimento na América Latina e, obviamente, na produção de Fernando Henrique Cardoso que a antecede e a sucede, é preciso abrir gavetas, ir às estantes e consultarlivros empoeirados, ler o que ninguém mais lê.A proposição forte da obra ébastante simples. O ponto de partida é a rejeição de que - eu cito - "nos países em desenvolvimento se esteja repetindo a história dos países desenvolvidos" 2 . Reconhecer hoje, para usar a linguagem corrente, a diversidade das rotas de desenvolvimento é, por assim dizer, trivial. Bem, o ovo teve que ser posto em pé pela primeira vez...

Contudo, não era trivial à época. Naquela quadra, essa afirmação colidia com os dogmas vigentes; questionava a suposição de uma história linear, evolucionista, única, na qual os países subdesenvolvidos estariam para os desenvolvidos como o macaco estaria para o homem, para fazer alusão a uma formulação célebre e que hoje não soa bem.

A teoria da dependência faz mais do que desafiar os dogmas caros ao marxismo e a sua "versão burguesa", a teoria da modernização. Não se contentou apenas com estilhaçar o estabelecido, fez mais que isso, mostrou-se capaz de recolher os cacos que produzira e reordená-los.

Não há uma rota única para o desenvolvimento. Há diferentes caminhos ou sequências. Opções, no entanto, são limitadas. Ou seja, há uns tantos caminhos possíveis e estes são determinados historicamente. Alternativas seguidas ontem limitam o conjunto de alternativas disponíveis hoje. Eessas escolhas incluem os regimes políticos.

A forma como estou reconstituindo a teoria da dependência mostra sua atualidade. Se usarmos o jargão corrente, se nos curvarmos aos modismos acadêmicos, se falarmos em pathdependence, criticaljunctures, punctuated equlibrium e correlatos é possível perceber como a matriz contida em Dependência e desenvolvimento se mantém, como resistiu ao tempo. A obra continua influente quase meio século após a sua publicação. Reconheçamos ou não, somos todos "dependentistas".

E são "dependentistas" autores insuspeitos. A influência de Cardoso e Faletto é substancial em autores como Douglass North, misto de historiador e economista laureado com o Prêmio Nobel. Em boa medida, partes consideráveis da contribuição de North podem ser lidas como traduções e adaptações da teoria da dependência ao jargão neoclássico. Em uma de suas primeiras obras, uma história dos Estados Unidos, North cita repetidamente a versão inglesa de Cardoso e 
Faletto. A matriz explicativa permanece atual. Continua sendo a referência para scholars que buscam explicar a divergência das experiências históricas em que desenvolvimento e regime político são tratados em conjunto. Não faltam exemplos dessa influência e de sua persistência. Tome-se o livro de Daron Acemoglu e James Robinson, Economic origins of dictatorship and democracy. Em que pesem as fórmulas matemáticas que pululam a cada página, a matriz, o cerne do modelo explicativo, não é outro senão aquele proposto por Fernando Henrique Cardoso, ainda que seu nome não conste da bibliografia.

O título da obra de Acemoglu e Robinson contém uma remissão imediata ao clássico de Barrington Moore, Social origins of dictatorship and democracy, obra publicada no mesmo ano que Dependência e desenvolvimento. A aproximação entre as duas obras, sobretudo nos termos em que estou a reconstituir a contribuição de Fernando Henrique Cardoso, é imediata e direta. Ainda assim, distinções devem ser feitas, e a novidade contida em Dependência e desenvolvimento deve ser sublinhada. Para ser sintético, eu diria que Cardoso e Faletto têm as respostas que Moore buscava, a saber, distinguir a rota a ser seguida pelos países em desenvolvimento. A Índia ocupa parte importante do livro de Moore. Fundamentalmente, o que ele quer saber é qual a rota do desenvolvimento a ser trilhado pela Índia e outros latecomers. Moore não chega, propriamente, a conclusões sobre o destino da Índia. Dependência e desenvolvimento, nesses termos, oferece uma resposta ao problema da combinação entre desenvolvimento e regime político que é mais abrangente e atual. Mais abrangente porque engloba a América Latina, cuja experiência não é discutida em Social origins. Mais atual porque atrela desenvolvimento capitalista a regimes autoritários em países de desenvolvimento tardio. Há desenvolvimento mesmo onde não há revoluções burguesas e/ ou camponesas. E há desenvolvimento capitalista. Por isso mesmo, a teoria da dependência pode ser transposta a outros contextos e regiões geográficas.

A linguagem mudou. O marxismo e a teoria da modernização cederam lugar à economia neoclássica, ao neoinstitucionalismo histórico.A matriz explicativa, o modelo, este permanece o mesmo. Podemos não perceber, não reconhecer, não mais citar Cardoso e Faletto como fazíamos no passado. Podemos, seguindo os modismos, preferir North, Acemoglu e Robinson, mas Dependência e desenvolvimento continua atual. As perguntas permanecem: por que alguns países se desenvolvem e outros não? O que explica a ocorrência de regimes democráticos e autoritários ao longo do tempo e do espaço? Como e por que desenvolvimento capitalista e democracia se combinam? Qual a relação entre subdesenvolvimento e autoritarismo? Como dar conta do atraso da América Latina? Quem quiser responder a essas perguntas hoje 
não terá escapatória. Comece por ler Dependência e desenvolvimento ou então estará fadado a inventar a roda.

Se nos concentrarmos no Brasil, na aplicação da teoria da dependência a nossa experiência histórica, temos que esta ofereceu a primeira explicação convincente para a instauração de um regime autoritário em 1964. A explicação oferecida permitiu conciliar os fatos à teoria. Isso porque, e isto pode soar totalmente absurdo hoje, as primeiras interpretações sobre o golpe enfatizavam seu lado reacionário, reacionário do ponto de vista econômico. Estaríamos diante de uma ditadura tradicional, comandada por forças tradicionais, pelo atraso. O latifúndio estaria por detrás do golpe. O latifúndio aliado ao imperialismo. Isso porque a industrialização do país ameaçaria ou iria contra o imperialismo.

Não é o caso de chateá-los com essa reconstituição. Tampouco cabe citar os inúmeros intelectuais que se aferraram a essa explicação convencional. Não pretendo arranhar imagens tão arduamente construídas. O fato é que não foram poucos os que não notaram o que a realidade mostrava de forma tão clara e incontrastável. $\mathrm{O}$ mundo mandava suas notícias e muitos recusavam a recebê-las. Por vezes, o problema não é a recusa à conversa com os adversários. Muitas vezes, o problema é de ordem inversa, é a insistência em ouvir apenas os que confirmam nossas ideias, é conversar apenas com os amigos. Quem assim procede acaba por recitar mantras.

Fernando Henrique Cardoso foi o primeiro a notar o caráter desenvolvimentista do regime, ligando o regime, usando seus próprios termos, às necessidades da nova fase de acumulação do capital no país. O ponto é conhecido e foi explicitado e desenvolvido por Fernando Henrique Cardoso em diversos artigos. Eu tenho que honrar meus compromissos e preciso ser breve. Estabelecido que a explicação do "modelo político brasileiro" comporta uma ruptura com a visão dogmática até então reinante, que a explicação oferecida concilia desenvolvimento econômico e industrialização nos marcos da divisão internacional do trabalho então reinante, que a derrocada da democracia populista se relaciona com essas transformações, tendo estabelecido esses pontos, ou melhor, tendo estabelecido que coube a Fernando Henrique apontar os nexos entre esses termos, eu passo para o próximo ponto ou momento da carreira intelectual de Fernando Henrique Cardoso: o confronto com sua própria teoria.

Se é possível dizer que a teoria da dependência e sua aplicação ao caso concreto da experiência política brasileira implicaram o desafio a dogmas estabelecidos, não será menos verdade reconhecer que essa mesma teoria poderia vir a se constituir em um novo dogma. Fernando Henrique foi o primeiro a tomar consciência e enfrentar as limitações da sua própria explicação. Os títulos de alguns de seus artigos falam 
por si: "O consumo da teoria da dependência nos Estados Unidos", "As novas teses equivocadas", "As desventuras da dialética da dependência". Há muitos outros.

O principal confronto, contudo, foi se desenvolvendo aos poucos. Um confronto com suas próprias ideias. Fernando Henrique, paulatinamente, se deu conta das consequências políticas contidas na sua explicação para a emergência e sustentação do novo modelo político. Porque há uma leitura possível da teoria da dependência que nos condena ao imobilismo político. Se o regime político é determinado pela estrutura econômica, seesta última é definida pelo caráter dependente do capitalismo, segue que a negação da dependência é uma condição necessária para a alteração da forma do regime. $\mathrm{O}$ autoritarismo seria a forma política necessária da dominação em sociedades dependentes.

De fato, no menu das opções históricas contempladas em Dependência e desenvolvimento na América Latina, não consta capitalismo dependente com democracia. $O$ socialismo popular, representado por Allende, é a única alternativa vislumbrada. As experiências históricas elencadas, na ausência de uma ruptura revolucionária, implicam a associação entre subdesenvolvimento e autoritarismo. Há assim um duplo enclausuramento no processo de desenvolvimento da América Latina, duplo porque econômico e político; o subdesenvolvimento e o autoritarismo persistem, resistem às transformações. Para escapar de ambos só uma ruptura. E a ruptura parece ser antes econômica que política. O capitalismoé dependente e associado porque a reprodução do capital não se dá internamente.

Não importa quão sofisticado fosse o marxismo praticado por Fernando Henrique Cardoso e seus pares. A relação causal entre capitalismo dependente e o regime político tinha que ser enfrentada. $O$ risco do determinismo continuava à espreita, pronto para dar o bote, reduzindo o requinte analítico da leitura estrutural do Capital a seus termos mais básicos. Nos texto que publica no período, Fernando Henrique Cardoso evita de forma hábil e cuidadosa uma interpretação economicista da emergência da ditadura militar. Os termos empregados para dar conta da relação entre desenvolvimento capitalista associado e regime político são escolhidos com um cuidado artesanal. Mas esse zelo não resolve o problema de fundo, pois deixa em aberto qual precisamente é a natureza da relação causal entre estrutura e superestrutura.A recusa a uma afirmação taxativa pode ser lida como um reconhecimento implícito das consequências envolvidas.

O fato é que em $O$ modelo político brasileiro, coletânea de artigos publicada em 1973, em que o artigo-título oferece a versão acabada oferecida por Fernando Henrique Cardoso para dar conta da emergência do regime militar, já nesse livro consta um artigo intitulado a "A questão democrática". Não é propriamente uma questão, mas sim uma pos- 
sibilidade. E é desta possibilidade que Fernando Henrique Cardoso vai se ocupar nos anos seguintes. O tema ocupa o centro de seu próximo livro. O seu título diz tudo:Autoritarismo e democratização. O título anuncia um programa de pesquisa, um compromisso, um engajamento político. O engajamento com o segundo termo, a democratização, leva progressivamente ao questionamento e abandono das categorias analíticas mobilizadas para dar conta do primeiro, da emergência do autoritarismo. A explicação para o primeiro termo, contudo, colide com a possibilidade do segundo.

Um pequeno detalhe na introdução desse livro não pode passar sem menção. Fernando Henrique apresenta seus artigos como ensaios e os justifica fazendo referência às "longínquas raízes lusitanas da nossa tradição cultural e legitimidade para os nossos esforços de síntese entre o analisar e o querer". Os ensaístas brasileiros Antonil, Alberto Torres, Euclides da Cunha, Oliveira Viana, Gilberto Freyre, são mencionados como exemplos seguidos. A pretendida ruptura entre a ciência e o ensaísmo que fornecera o ethos no qual a escola sociológica paulista buscou se legitimar é, portanto, reconsiderada, posta em xeque. O momento é outro.

A possibilidade, a mera possibilidade, da democratização pede uma ruptura no plano das ideias. Como dar conta da possibilidade da emergência de uma ordem política democrática, por minimamente democrática que seja esta ordem, em uma sociedade periférica? A partir desse livro, os artigos acadêmicos de Fernando Henrique Cardoso, muitos deles publicados na revista do Cebrap, ganham um caráter que, na falta de melhor termo, chamarei de exploratórios. Talvez fosse mais apropriado dizer investigativos. Isso porque os artigos revelam uma abertura às mais diferentes perspectivas analíticas disponíveis, uma disposição a testar o alcance de explicações emergentes e alternativas. Em diversas passagens desses textos, Fernando Henrique Cardoso afirma a necessidade imperiosa de se construir um novo paradigma, uma nova teoria que seja capaz de oferecer as balizas necessárias para a construção política com que a sociedade brasileira se defronta. Quero ressaltar essa inquietação intelectual, o movimento incessante ditado pelas notícias que são dadas pela realidade, a necessidade de ter respostas para as questões e opções concretas.

Tão logo nos apresenta uma explicação convincente para a emergência do autoritarismo, Fernando Henrique Cardoso se põe em campo para examinar a possibilidade de sua derrocada. E ao fazê-lo, ao estudar e buscar entender os rumos possíveis de, naquele momento, um remoto e incerto processo de democratização, afasta-se progressivamente da teoria da dependência. $\mathrm{O}$ mundo voltara a mandar notícias. A realidade mudou, se moveu, e se moveu de forma incompatível com a teoria. 
Neste ponto, cabe mencionar a importância que o Cebrap desempenhou na conversão teórica que a realidade política impôs. E aqui se revela outro aspecto importante da contribuição intelectual de Fernando Henrique Cardoso. O Cebrap, sob sua liderança, esteve sempre aberto a se reciclar, a abrir suas portas, acolhendo cientistas sociais com as mais diversas formações. O Cebrap não foi uma extensão da Maria Antônia. Tampouco a versão institucionalizada do grupo de leitura do Capital. O Cebrap foi muito mais que isso. Seu papel para a renovação das ciências sociais ainda está por ser escrito. Mas o que eu queria ressaltar no momento é um fato bem palmar e pedestre. Muita gente formada fora da UsP veio a trabalhar no Cebrap. Além de multidisciplinar, o Cebrap sempre esteve aberto a receber intelectuais com formações diversas. Não fiz pesquisa, mas vêm à minha memória os nomes de Francisco de Oliveira, Carlos Estevão Martins, Vilmar Faria, Bolívar Lamounier. Sei que posso estar cometendo injustiças, esquecendo nomes que não poderiam deixar de ser mencionados. Cito os que trabalharam com os temas afins à reconstituição que ofereço. As injustiças que certamente cometi, essas omissões injustificáveis, contudo, só reforçam o meu ponto: o Cebrap não se fechou. Como me disse certa vez a Elza Berquó, a marca maior do Cebrap sempre foi seu ecumenismo analítico.

A tarefa a ser enfrentada pedia a mobilização de um novo arsenal.A leitura estrutural do Capital, a exegese de Marx, não traria as respostas para as perguntas que se colocavam. E isto é reconhecido, implícita e explicitamente, nos artigos de Fernando Henrique Cardoso do período. Era preciso se abrir para o diálogo intelectual. Era preciso beber em novas fontes se havia pretensão de contribuir para a construção de uma democracia.

Uma vez mais, o mundo mandava notícias demandando respostas que implicavam romper com dogmas. E a demanda tinha caráter urgente. Era para hoje. $\mathrm{O}$ processo político ganhou uma celeridade inesperada, surpreendente. O início do processo de distensão, posteriormente rebatizado de abertura, e os resultados surpreendentes da eleição de 1974 não figuravam no radar de qualquer analista. A resposta do Cebrapé imediata, no ato, de bate-pronto. A análise estrutural do capitalismo cede lugar à pesquisa de opinião. Mas não é o método que importa destacar aqui. O que merece ênfase é a capacidade de se pôr em campo, de respondere processar as notícias quevinham do mundo. E não se tratou de dar uma resposta qualquer. Os artigos de Vilmar Faria, Bolívar Lamounier e Fernando Henrique Cardoso publicados em Os partidos e as eleições no Brasil não explicam apenas a surpresa das urnas, eles vão muito além, eles são prospectivos, indicam rumos. Por assim dizer, está tudo ali. Para os interessados em estudar o processo de redemocratização, esta é a obra, a referência. Repito: está tudo ali.A 
redemocratização poderia e iria caminhar pela via eleitoral. No médio prazo, o regime seria derrotado eleitoralmente.

A superestrutura se vingara da estrutura. E essa vingança tinha sabor amargo para os que não acreditavam que esse descolamento seria possível. A realidade se impôs. O Cebrap, como todos sabemos, engajou-se de forma direta na luta pela democracia desde seu início. Antes mesmo da eleição de 1974, se não me engano, líderes do então MDB, procuram o Cebrap para que este colaborasse na elaboração do programa do partido. A participação não se resumiu à política partidária. Não há como deixar de mencionar São Paulo:crescimento e pobreza e seu impacto sobre a desconstrução da imagem que o regime autoritário buscara construir. $O$ milagre econômico gerara pobreza. $\mathrm{O}$ santo tinha pés de barro. O rei foi apresentado em sua nudez descarada. Mas essa é uma longa história. Não outra história, posto que é a história que Fernando Henrique ajudou a construir. Mas é longa demais para que eu seja breve.

Fernando Henrique Cardoso criou uma instituição que soube se renovar e que sob sua liderança ofereceu respostas aos problemas postos na agenda do dia. As contribuições que estou destacando apontam em uma única direção, a da abertura intelectual, a da disposição para se renovar recusando o pensamento dogmático. Características, vale lembrar, que Fernando Henrique Cardoso já havia demonstrado no Conselho Universitário da USP nos anos 1960. Ouvir argumentos, entender a natureza das ideias para, então, fazer um estrago, para usar a expressão do Giannotti.

Creio poder concluir notando que esta é a marca maior da obra intelectual construída por Fernando Henrique Cardoso, a fuga à resposta convencional. Por isto mesmo, porque capaz de ouvir, porque capaz de distinguir as ideias da sua autoria, por isto mesmo, Fernando Henrique foi capaz de construir uma obra. Uma obra construída em tempos difíceis, em tempos de golpes, de violência e intolerância. Tempos adversos.

Fernando Henrique Cardoso nunca deixou de aceitar e enfrentar os desafios. Esteve sempre aberto a ouvir as notícias do mundo, permaneceu fiel aos ensinamentos recebidos de seu pai. É preciso conversar com todos, até com o carcereiro. Fernando Henrique Cardoso, porque sempre se mostrou disposto ao debate intelectual e político, soube onde estava o novo. Antes dos demais. Sorte nossa.

FERNANDO Limongi é professor titular do departamento de Ciência Política da FFLCH-USP e pesquisador do Cebrap. 